\title{
Solitary Lesions on Bone Scintigraphy in Patients with Breast Cancer: King Abdulaziz University Medical Centre Experience
}

\author{
Nadia A. Batawil, MD, FEBNM \\ Department of Radiology, Division of Nuclear Medicine \\ Faculty of Medicine, King Abdulaziz University, Jeddah, Saudi Arabia
}

\section{Correspondence}

Dr. Nadia A. Batawil

P.O. Box 80215, Jeddah 21589, Saudi Arabia

e.M: nbatawil@kau.edu.sa

Submission: 14 October 2014

Accepted: 21 December 2014

\section{Citation}

Batawil NA. Solitary lesions on bone scintigraphy in patients with breast cancer King Abdulaziz University Medical Centre experience. JKAU Med Sci 2015; 22(1): 9-16. DOI: 10.4197/

Med. 22.1.2

\begin{abstract}
The discrepancy between bone scintigraphy and computed tomography scanning for solitary bony lesion in patients who have breast cancer is challenging to the referral physician. The purpose of this study was to evaluate the risk of malignancy in solitary lesions on bone scintigraphy in patients who had breast cancer diagnosed at King Abdulaziz University Medical Centre, and to compare the results between bone scintigraphy and computed tomography scanning. There were 89 patients who had a solitary bone lesion noted on bone scintigraphy and computed tomography performed within 3 months of bone scintigraphy. The solitary bone lesions were benign in $56(63 \%)$ patients and malignant in 33 patients (37\%). There were $15(17 \%)$ malignant lesions in bone scan that had initial computed tomography findings that were negative or equivocal for bone metastasis, but all these lesions had destructive changes on follow-up computed tomography scan. In summary, at this medical center the frequency of malignancy is high (37\%) in solitary bone lesions in patients who have breast cancer, regardless of appearance of the lesion on an initial computed tomography scan. Prospective study with a larger group of patients is recommended.
\end{abstract}

\section{Keywords}

Metastasis, Malignant, Computed tomography.

\section{INTRODUCTION}

he skeleton is the most common site for distant metastasis from breast cancer. The risk of skeletal metastasis as assessed by bone scintigraphy is $0.8 \%$ to $2.6 \%$ for stage 1 and 2 and $16.8 \%$ to $40 \%$ for stage 3 and $4^{[1,2]}$. Staging of breast cancer is used to direct therapeutic decisions and provide important prognostic information. When bone metastasis is suspected, bone scintigraphy and computed tomography (CT) are commonly used for proper staging. Bone metastases usually are multiple, and solitary skeletal metastasis is observed in $21 \%$ to $41 \%$ of patients ${ }^{[3,4]}$. Radiographic correlation of the site of solitary uptake of radioisotope is necessary and enables precise anatomic and morphologic characterization.

Bone scintigraphy is sensitive in detecting skeletal metastatic lesions, but the specificity is low because benign conditions may cause increased radioisotope uptake including trauma, infection, and arthritis ${ }^{[5,6]}$. Chest and abdominal CT scans are usually performed 
to assess visceral and skeletal metastasis. The discrepancy in the metastatic workup for solitary bony lesion between negative CT scan and positive bone scan is challenging, particularly with the advanced CT resolution and low bone scan sensitivity. One study suggests that CT scan of chest and abdomen with the extension of the scan to the pelvis may increase CT scan sensitivity (98\%) and specificity (100\%) for skeletal metastasis, and CT scanning may replace the bone scan during the initial evaluation ${ }^{[7]}$. However, in a systematic review of 16 studies that compared the accuracy of imaging tests for bone metastasis in women who had breast cancer, there was little evidence that $\mathrm{CT}$, magnetic resonance imaging (MRI), or fluorodeoxyglucose positron emission tomography (FDG-PET) scans may replace bone scan in the initial imaging for bone metastasis ${ }^{[8]}$. The MRI scans had higher sensitivity (97\%) and specificity (97\%) than FDG-PET (sensitivity $83 \%$, specificity $94.5 \%$ ) or bone scintigraphy (sensitivity $87 \%$, specificity $88 \%$ ) in diagnosis of bone metastasis in patients who had breast cancer ${ }^{[9]}$. Nevertheless, MRI is not commonly used for initial or follow-up evaluation in patients who have breast cancer because of restricted availability, high cost, and the long duration of whole -body MRI scanning.

The purpose of the present study was to evaluate the frequency of malignancy in solitary lesions on bone scintigraphy in patients who had breast cancer, and to compare the results between bone scintigraphy and CT scanning of the chest, abdomen and pelvis for evaluation of bone metastases. This study reviews the clinical history and follow-up CT scan and bone scintigraphy studies to determine the incidence of cancer in solitary bony lesions, the effect of clinical factors on the course of solitary metastatic bone lesions, and to compare the accuracy of bone scintigraphy and CT scan for imaging solitary bone metastasis in patients who had breast cancer.

\section{Materials and Methods}

\section{Subjects}

This study retrospectively reviews all bone scintigraphy studies performed for staging in patients who had the clinical diagnosis of breast cancer at the Nuclear Medicine Department, King Abdulaziz University Hospital, between January 2007 and December 2011. Patients were included in the study when they had: (1) A single area of radioisotope uptake on bone scintigraphy that had the appearance of a bone metastasis; (2) A CT scan performed within 3 months of the bone scintigraphy study that evaluated the site of abnormal radioisotope uptake; and (3) $\geq$ 1 follow-up bone scintigraphy study and CT scan. There were 720 bone scintigraphy studies performed among 434 patients who had breast cancer to screen for metastasis: No metastasis in 215 (50\%) patients; solitary bone lesions in 132 (30\%) patients; multiple skeletal metastases in $87(20 \%)$ patients. Of the 132 patients who had solitary bony lesions, 43 patients (33\%) were excluded (CT correlation not available for 23 patients; 20 patients lost to follow-up), leaving 89 patients included in the study who had solitary bone lesions on bone scintigraphy and an available initial CT scan performed within 3 months of bone scintigraphy.

\section{Evaluation}

Medical records were reviewed for age, tumor markers, follow-up, extraosseous metastasis, and progression to multiple skeletal metastasis. The incidence of malignancy in the solitary bone scintigraphic abnormality was assessed from the follow-up bone scintigraphy study and CT scan. Any available plain radiographs and MRI scans were reviewed for the detected solitary lesion.

\section{Bone Scintigraphy and Computed Tomography}

Whole body bone scintigraphy was performed at 3 to 4 hours after intravenous injection of technetium Tc 99 methyldiphosphonate (740-925 MBq [20-25 mCi]). Anterior and posterior total body, static lateral skull and oblique chest images were obtained. Selected spot views with or without single photon emission $\mathrm{CT} / \mathrm{CT}$ of the abnormal site were acquired as needed. Images were acquired with a dual head gamma camera (Skylight, Philips, Best, The Netherlands) or hybrid single photon emission CT/CT dual head gamma camera (Symbia T6, Siemens, Munich, Germany). Images were acquired with a low-energy, high-resolution collimator (photopeak $140 \mathrm{kev}, 20 \%$ symmetrical window, matrix size $256 \times 1024)$.

The CT scans were performed after oral and intravenous contrast administration (Somatom, Siemens 64 slices and Definition AS, Siemens 128 slices). Images were acquired with multislice technique (slice thickness, $5 \mathrm{~mm}$ ) and reconstruction protocol for the chest $(1.5 \mathrm{~mm})$ and abdomen and pelvis $(2 \mathrm{~mm})$. 
The diagnostic criteria for solitary skeletal metastasis included a single area of increased uptake of radioisotope on bone scintigraphy and a CT abnormality at the same anatomic location that was either (1) a destructive lesion on the CT scan performed within 3 months of bone scintigraphy or (2) a normal or equivocal initial CT scan and a destructive lesion on the follow-up CT scan consistent with metastasis. The diagnostic criteria for a benign solitary lesion included a single area of increased uptake of radioisotope on bone scintigraphy and either (1) corresponding CT changes consistent with benign disease such as arthritis or trauma or (2) improved or stable uptake on follow-up bone scintigraphy and normal CT scan appearance throughout follow-up.

\section{Data Analysis}

Pearson chi-square $\left(\chi^{2}\right)$ test and Fischer exact test were used to evaluate the relation between the incidence of solitary metastatic lesions and other clinical factors such as age, tumor markers, stage, and visceral and extra skeletal metastasis. The relation between a solitary area of increased uptake on bone scintigraphy and CT findings (initial CT normal or abnormal) was evaluated. Statistical significance was defined as $P \leq$ .05 .

\section{Results}

The 89 patients who had abnormal solitary lesions on bone scintigraphy had a total 193 bone scintigraphy studies and 222 CT scans performed during followup (mean 3.2 yrs., range 1-5 yrs.). Most lesions were benign (Table 1). Malignant lesions were associated more frequently with elevated levels of tumor markers, visceral metastases, and progression to multiple skeletal metastases than benign lesions (Table 1). Mean age was similar between patients who had benign or malignant lesions (Table 1).

Most solitary lesions were located in the spine, ribs, or sternum, and differences in frequency between benign and malignant lesions in these locations were not significant (Table 1). Most metastatic lesions were located in the spine, ribs, or sternum (Table 2). 38 (43\%) patients had solitary lesions with equivocal findings for metastasis in the initial CT scan. At follow-up 15 (39\%) lesions were malignant and 23 (61\%) lesions were benign (not significant).

Table 1. Clinical characteristics of patients who had breast cancer and solitary uptake of radioisotope on bone scintigraphy*

\begin{tabular}{|c|c|c|c|c|}
\hline Characteristics & Total & Malignant & Benign & $P \leq^{\dagger}$ \\
\hline No. of Patients & $89(100)$ & $33(37)$ & $56(63)$ & NS \\
\hline $\begin{array}{l}\text { Age } \\
\begin{aligned}>45 y \\
<45 y\end{aligned}\end{array}$ & $\begin{array}{l}61(69) \\
28(31) \\
\end{array}$ & $\begin{array}{c}25(41) \\
8(29) \\
\end{array}$ & $\begin{array}{l}36(59) \\
20(71) \\
\end{array}$ & NS \\
\hline $\begin{array}{r}\text { Tumor Markers }^{\ddagger} \\
\text { Elevated } \\
\text { Normal }\end{array}$ & $\begin{array}{l}24(27) \\
65(73)\end{array}$ & $\begin{array}{c}17(71) \\
1(25)\end{array}$ & $\begin{array}{c}7(29) \\
49(75)\end{array}$ & .0001 \\
\hline $\begin{array}{l}\text { Visceral Metastasis } \\
\text { Yes } \\
\text { No } \\
\end{array}$ & $\begin{array}{l}21(24) \\
68(76) \\
\end{array}$ & $\begin{array}{l}14(67) \\
19(28) \\
\end{array}$ & $\begin{array}{c}7(33) \\
49(72) \\
\end{array}$ & .001 \\
\hline $\begin{array}{l}\text { Progression to Multiple Skeletal Metastasis } \\
\text { Yes } \\
\text { No }\end{array}$ & $\begin{array}{l}23(26) \\
66(74) \\
\end{array}$ & $\begin{array}{l}18(78) \\
15(23) \\
\end{array}$ & $\begin{array}{c}5(22) \\
51(77)\end{array}$ & .001 \\
\hline $\begin{array}{l}\text { Computed Tomography } \\
\text { Positive } \\
\text { Negative/Equivocal } \\
\end{array}$ & $\begin{array}{l}51(57) \\
38(43) \\
\end{array}$ & $\begin{array}{l}18(35) \\
15(39) \\
\end{array}$ & $\begin{array}{l}33(65) \\
23(61)\end{array}$ & NS \\
\hline $\begin{array}{l}\text { Anatomic Distribution } \\
\text { Spine } \\
\text { Ribs } \\
\text { Sternum } \\
\text { Femur } \\
\text { Skull } \\
\text { Clavicle }\end{array}$ & $\begin{array}{c}48(54) \\
26(29) \\
8(9) \\
3(3) \\
3(3) \\
1(1)\end{array}$ & $\begin{array}{l}20(42) \\
7(27) \\
4(50) \\
1(33) \\
1(33) \\
0(0)\end{array}$ & $\begin{array}{l}28(58) \\
19(73) \\
4(50) \\
2(67) \\
2(67) \\
1(100)\end{array}$ & $\begin{array}{l}\text { NS } \\
\text { NS } \\
\text { NS } \\
\text { NS } \\
\text { NS } \\
\text { NS }\end{array}$ \\
\hline
\end{tabular}


The follow-up CT scan showed destructive changes consistent with metastasis in all 33 malignant lesions, with high overall sensitivity $(100 \%)$ and specificity (100\%) for bone metastasis. In 15 (45\%) malignant lesions the initial CT findings were equivocal for bone metastasis, but follow-up CT scan showed destructive changes and bone scintigraphy showed persistent increased scintigraphic uptake (Figs. 1 and 2). Progression to multiple skeletal metastasis was observed in 15 (45\%) patients, including 9 patients who

Table 2. Clinical and computed tomography characteristics of patients who had breast cancer and solitary malignant bone lesions on bone scintigraphy*.

\begin{tabular}{|c|c|c|c|c|}
\hline \multirow[b]{2}{*}{ Characteristic } & \multicolumn{3}{|c|}{ Initial Computed Tomography Scan } & \multirow[b]{2}{*}{$P \leq^{\dagger}$} \\
\hline & Total & Positive & $\begin{array}{l}\text { Negative/ } \\
\text { Equivocal }\end{array}$ & \\
\hline No. of Patients & $33(100)$ & $18(55)$ & $15(45)$ & NS \\
\hline Age $(\mathrm{Y})$ & & $51 \pm 12$ & $55 \pm 13$ & NS \\
\hline \multicolumn{5}{|l|}{ Anatomic Distribution } \\
\hline Spine & $20(61)$ & $11(55)$ & $9(45)$ & NS \\
\hline Ribs & $7(21)$ & $3(43)$ & $4(57)$ & NS \\
\hline Sternum & $4(12)$ & $2(50)$ & $2(50)$ & NS \\
\hline Femur & $1(3)$ & $1(100)$ & $0(0)$ & NS \\
\hline Skull & $1(3)$ & $1(100)$ & $0(0)$ & NS \\
\hline Tumor Markers Elevated & $17(52)$ & $11(65)$ & $6(35)$ & NS \\
\hline Visceral Metastasis & $14(42)$ & $6(43)$ & $8(57)$ & NS \\
\hline Progression to Multiple Skeletal Metastasis & $15(45)$ & $6(40)$ & $9(60)$ & NS \\
\hline
\end{tabular}

${ }^{*} \mathrm{~N}=33$ patients who had malignant solitary bone lesions. Data reported as number (\%) or mean \pm SD.

${ }^{\dagger} \mathrm{NS}$, not significant $(P>.05)$.
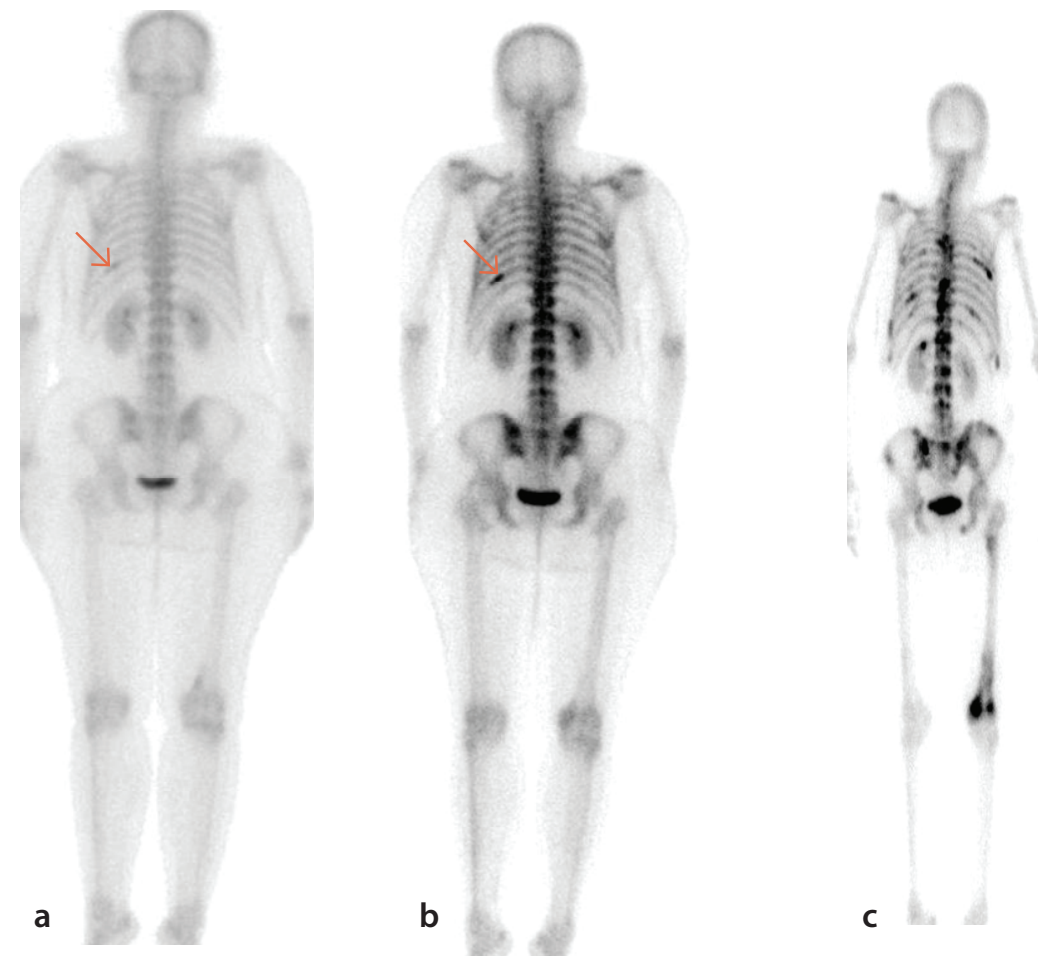

Figure 1. Bone scintigraphy (BS) in a patient who had breast cancer for initial staging. (a) Base line BS demonstrated a solitary uptake at the left 9th rib posteriorly (arrow). (b) Follow up BS at 6 months demonstrated stable skeletal metastasis at the left 9th rib (arrow). (c) Follow up BS at 22 months showed multiple skeletal metastasis at axial and appendicular skeleton. 

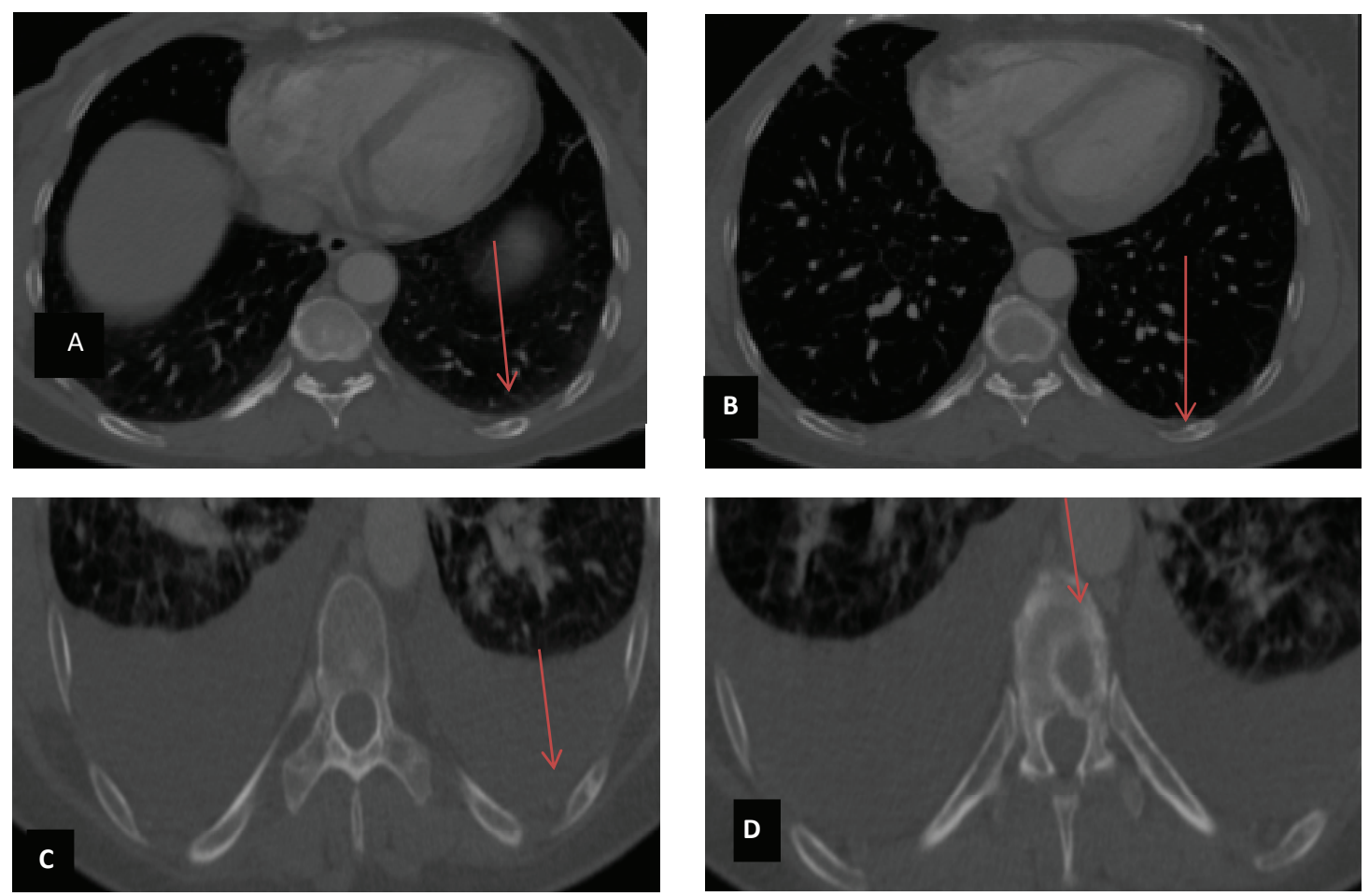

Figure 2. Correlative computed tomography of the chest in a patient who had breast cancer (Fig 1). (a) The initial computed tomography scan for staging (8 weeks after BS) had a faint cortical irregularity at the left 9th rib that was interpreted as likely traumatic. (b) Follow-up computed tomography scan at 6 months showed stable appearance of the left 9th rib. (c, d) Follow-up computed tomography scan at 24 months showed a stable appearance of the left 9th rib (c) and a lytic skeletal metastasis at the lumbar spine(d).

had initial negative or equivocal CT and 6 patients who had a positive initial CT scan for metastasis (difference not significant) (Table 2). There was no significant difference in the frequency of elevated tumor marker levels or the frequency of visceral metastasis between patients who had positive or negative initial CT scan (Table 2). There were 31 patients (35\%) who had single photon emission CT/CT and 11 (12\%) patients who had MRI to analyze the solitary area of increased uptake on bone scintigraphy.

\section{Discussion}

The present study showed that the frequency of solitary skeletal metastasis in breast cancer patients was $37 \%$ (Table 1), which is comparable to data from one previous study $(41 \%)^{[3]}$ and higher than data from another study $(21 \%)^{[4]}$. The difference in the frequency between studies may be attributed to the short followup period between bone scintigraphy and $\mathrm{CT}$ scanning in the present study (3-6 months). Clinical analysis alone is not adequate to diagnose skeletal metastasis because $30 \%$ to $50 \%$ of patients do not have symptoms of metastatic disease when they present with breast cancer ${ }^{[10]}$. The tumor markers are simple, commonly available, cost-effective tests for follow-up in patients who have breast cancer metastasis, but data vary about the correlation between tumor markers and bone metastasis ${ }^{[11,12]}$. In the present study, patients who had a malignant solitary lesion had elevated levels of tumor markers (cancer antigen 15 or carcinoembryonic antigen) over patients who had benign lesions (Table 1). Patients who initially had a malignant solitary lesion more frequently developed multiple skeletal metastases and visceral metastasis than patients who initially had a benign lesion (Table 1).

Most bone metastases begin as intramedullary lesions, and most red marrow is located in the axial skeleton (vertebrae, pelvis, and proximal femurs). Breast cancer may metastasize preferentially to these regions because the spine is highly vascularized and contains $75 \%$ body bone marrow. Metastatic tumor cells may infiltrate the vertebral body bone marrow without destroying the cortical bone ${ }^{[13]}$. The spine also may develop facet joint arthritis, fractures, and 
degenerative disk disease. In the present study $58 \%$ of vertebral lesions were benign and $42 \%$ of vertebral lesions were malignant (Table 1). The anatomic distribution of the solitary bone lesion throughout the skeleton was similar between benign and malignant lesions (Table 1). Metastatic vertebral lesions were observed in most malignant solitary lesions (Table 2), and spine metastases frequently originated from the lumbar spine (50\%). One previous study of 289 solitary metastatic lesions in breast cancer patients showed that $32 \%$ of lesions were in the vertebrae $\mathrm{e}^{[3]}$ and another study showed that $50 \%$ of vertebral lesions were metastatic ${ }^{[10,14]}$.

The CT scan is a powerful method to delineate bone metastasis with high sensitivity and specificity ${ }^{[7,8]}$. With a high CT resolution, it was suggested that routine bone scans are not required in staging patients with advanced breast cancer, as the bone scan did not identify any metastatic lesion that was missed by $\mathrm{CT}$ scan $^{[7]}$. However, a CT scan may not show early bone metastasis or may show equivocal changes that can be missed by the interpreter. In the present study 38 patients (43\%) presented with initially negative or equivocal CT correlation, corresponding with the solitary scintigraphic finding; 15 of those patients (39\%) had metastatic disease in follow-up bone scintigraphy and CT scans. Both CT-negative and CT-positive groups had destructive changes consistent with metastasis in the follow-up CT scan and had comparable frequency of visceral metastasis and conversion from single metastasis to multiple skeletal metastasis (Table 2). Bone metastasis may start as an intramedullary lesion, and the CT scan may be normal in patients who have early bone metastasis and may not detect structural changes ${ }^{[13]}$. Early detection of skeletal metastasis may enable early treatment and possibly longer survival time, but the early CT scan may be negative. Therefore in patients who have early metastasis, more aggressive therapy may be recommended solely on the basis of positive scintigraphy ${ }^{[10]}$.

Limitations of the present study include the retrospective design and small number of patients that may have limited statistical power. Nevertheless, this study confirms that the frequency of metastasis at this medical center is high in patients who have breast cancer and a solitary bone lesion detected with bone scintigraphy (37\%), and the spine is the most common site of metastases (61\%). Bone metastasis with initial negative or equivocal CT scan and positive scintigraphy occurred in 15 of 89 patients (17\%). A prospective study with a larger group of patients is recommended.

\section{Acknowledgment}

The author expresses her gratitude to Dr. Iskander Algithmi for his outstanding support.

\section{Funding}

None.

\section{Disclosure summary}

The authors have nothing to disclose.

\section{References}

[1] Yeh KA, Fortunato L, Ridge JA, Hoffman JP, Eisenberg BL, Sigurdson ER. Routine bone scanning in patients with $\mathrm{T1}$ and 12 breast cancer: a waste of money. Ann Surg Oncol 1995; 2(4): 319-324.

[2] Schirrmeister H, Guhlnamm A, Kotzerke J, Santjohanser C, Kuhn T, Kreienberg R, Messer P, Nussle K, Elsner K, Glatting G, Trager H, Neumaier B, Diederichs C, Reske SN. Early detection and accurate description of extent of metastatic in breast cancer with fluoride ion and positron tomography. J Clin Oncol 1999; 17: 2381-2389.

[3] Koizumi M, Yoshimoto M, Kasumi F, Ogata E. Comparison between solitary and multiple skeletal metastatic lesions of breast cancer patients. Ann Oncol 2003; 14(8): 1234-1240.

[4] Boxer DI,Todd CE, Coleman R, Fogelman I. Bone secondaries in breast cancer: the solitary metastasis. J Nucl Med 1989; 30(8): 1318-1320.

[5] Jacobson AF, Fogelman I. Bone scanning in clinical oncology: does it have a future? Eur J Nucl Med 1998; 25(9): 1219-1223.

[6] Gayed I, Vu T, Johnson M, Macapinlac H, Podoloff D. Comparison of bone and 2-deoxy-2-[18F]fluoro-D-glucose positron emission tomography in the evaluation of bony metastases in lung cancer. Mol Imaging Biol 2003; 5(1): 2631.

[7] Bristow AR, Agrawal A, Evans AJ, Burrell HC, Cornford EJ, James JJ, Hamilton L, Robertson JF, Chan SY, Lawton PA, Cheung KL. Can computerized tomography replace bone scintigraphy in detecting bone metastases from breast cancer? A prospective study. Breast 2008; 17(1): 98103.

[8] Houssami N, Costelloe CM. Imaging bone metastases in breast cancer: evidence on comparative test accuracy. Ann Oncol 2012; 23(4): 834-843.

[9] Liu T, Cheng T, Xu W, Yan WL, Liu J, Yang HL. A meta-analysis of 18FDG-PET, MRI and bone scintigraphy for diagnosis of bone metastases in patients with breast cancer. Skeletal Radiol 2011; 40(5): 523-531.

[10] Maffioli L, Florimonte L, Pagani L, Butti I, Roca I. Current role of bone scan with phosphonates in the follow-up of breast 
cancer. Eur J Nucl Med Mol Imaging 2004; 31 (Suppl 1): S143-148.

[11] Nicolini A, Ferrari P, Sagripanti A, Carpi A. The role of tumour markers in predicting skeletal metastases in breast cancer patients with equivocal bone scintigraphy. Br J Cancer 1999; 79(9-10): 1443-1447.

[12] Yildiz M, Oral B, Bozkurt M, Cobaner A. Relationship between bone scintigraphy and tumor markers in patients with breast cancer. Ann Nucl Med 2004; 18(6): 501-505.

[13] Bilsky MH1, Lis E, Raizer J, Lee H, Boland P. The diagnosis and treatment of metastatic spinal tumor. Oncologist 1999; 4(6): 459-469.

[14] Hamaoka T, Madewell JE, Podoloff DA, Hortobagyi GN, Ueno NT. Bone imaging in metastatic breast cancer. J Clin Oncol 2004; 22(14): 2942-2953. 


\title{
تجارب المركز الطبي لجامعة الملك عبدالعزيز في تشخيص الآفة العظمية المنفردة لمرضى سرطان الثدي
}

\author{
نادية عبدالله باطويل \\ قسم الأشعة، كلبة الطب، جامعة الدلك عبد العزيز \\ جذة ـ المدلكة العربية السعودية
}

المستخلص. التناقض بين أشعة الفحص النووي للعظام ومسح التصوير المقطعي لمنطقة عظمية منفردة في الأشعة النووية للمرضى الذين يعانون من سرطان الثذي يثكل تحديا للأطباء. الغرض من هذه الدراسة هو تقييم خطر انتشار السرطان لمنطقة منفردة في العظام اكتشفت في الأشعة النووية في مرضى سرطان الثدي في مستشفى جامعه الملك عبدالعزيز، كان هنالك 9 مريضا لوحظت لايهم تغير ات في عظمة منفردة بالأشعة النووية وقورنت بالتصوير المقطعي الذي تم في

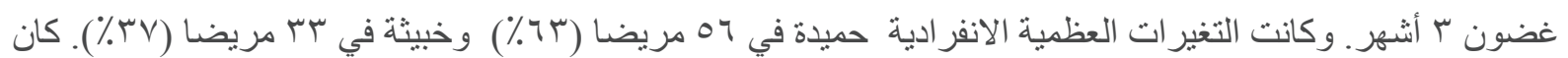
هنالك 10 انتشار آ عظمياً خبيثًا (V (1) في فحص العظام النووي التي كانت نتائج التصوير المقطعي الأولية له سلبية أو مبهمة ولكنها كانت و اضحه كانتشار سرطاني عظمي في متابعة المسح المقطعي. وباختصار ، فإن نسبه الانتشار الخبيث عالية (vr\%) في التغير ات العظمية المنفردة في المسح النووي عند المرضى الذين يعانون من سرطان الثدي في المركز الطبي الجامعي، بغض النظر عن ظهورها واضحة على مسح التصوير المقطعي الأولي. لذا، ينصح بمزيد من التقييم

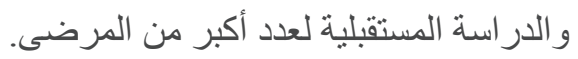

